Saudi Journal of Oral and Dental Research

Abbreviated Key Title: Saudi J Oral Dent Res

ISSN 2518-1300 (Print) |ISSN 2518-1297 (Online)

Scholars Middle East Publishers, Dubai, United Arab Emirates

Journal homepage: https://saudijournals.com/sjodr

\title{
Evaluation of Efficacy and Pain in Open Mouth versus Closed Mouth Ianb Technique for Third Molar Extraction
}

Dr. Sangeetha Karunakaran, BDS ${ }^{1 *}$, Dr. Alankrutha Gangasani, B.D.S ${ }^{2}$, Dr. Priyanka Unnam, BDS ${ }^{3}$, Dr. Asha Sri Sai Sunkara, BDS ${ }^{4}$, Dr. Aishwarya Rani Samyuktha Dasari, BDS ${ }^{5}$, Dr. Gurinder Kaur, BDS ${ }^{6}$

${ }^{1}$ Sri Ramakrishna Dental College and Hospital, Coimbatore, Tamil Nadu, India

${ }^{2}$ Panineeya Mahavidyalaya Institute of Dental Sciences and Research Center, Hyderabad, Telangana, India

${ }^{3}$ Narayana Dental College and hospital, Nellore, Andhra Pradesh, India

${ }^{4}$ Dr. Sudha \& Nageswara Rao Siddhartha Institute of Dental Sciences, Andhra Pradesh, India

${ }^{5}$ Government Dental College and Hospital, Vijayawada, India

${ }^{6}$ Bhojia dental college and hospital, Baddi, Himachal Pradesh, India

\author{
DOI: $10.36348 /$ sjodr.2020.v05i07.003 \\ | Received: 25.06.2020 | Accepted: 06.07.2020 | Published: 12.07.2020
}

*Corresponding author: Dr. Sangeetha Karunakaran, BDS

\section{Abstract}

\begin{abstract}
Aim: The purpose of the present study was to assess the efficacy as well as pain perception status in patients, who have been administrated Inferior Alveolar Nerve Block (IANB) for third molar extraction by both closed mouth as well as open mouth techniques. Methodology: 90 patients were enrolled in the present study. The patients were given inferior alveolar nerve block to extract mandibular third molar by three different techniques. They were divided in 3 groups of 30 patients each in which conventional open mouth, Fischer 123 technique, closed mouth Vazirani Akinosi technique were assigned with Group I, II, III respectively. Pain Perception (VAS), Speed of anaesthesia, Patient anxiety and Clinician expertise were measured. Results: The results show that intra-oral conventional technique is less technique sensitive as compared to Vazirani-Akinosi and Fischer's 123 techniques. Former is still the best in terms of less expertise required as well as pain perception by the patient. Conclusion: Conventional open mouth technique is still the most popular choice amongst clinicians and the pain sensitivity is also negligible amongst the patients with this classic intra-oral technique. Indirect as well as closed mouth technique requires more skilled expertise but can be used in cases with limited mouth opening.
\end{abstract}

Keywords: Local Anesthesia, Inferior Alveolar Nerve Block, Visual Analogue Scale.

Copyright @ 2020: This is an open-access article distributed under the terms of the Creative Commons Attribution license which permits unrestricted use, distribution, and reproduction in any medium for non-commercial use (NonCommercial, or CC-BY-NC) provided the original author and source are credited.

\section{INTRODUCTION}

The term anesthesia was introduced by Oliver W Holmes in 1846 which means the loss of pain sensation (pain), accompanied or not accompanied with loss of consciousness. Anesthesia has long been known as an effort to facilitate surgery. Anesthetic technique which is often used in the field of dentistry is topical anesthetic technique, infiltration technique and block techniques [1]. (Figure 1) Mandibular third molar extraction is one of the most commonly performed procedures in dentistry. Most patients' primary concern is pain during dental extraction. Pain control is an essential part of dental extraction, and the most common method of pain control is local anaesthesia. Local anaesthesia may be categorized in a number of ways according to the extent of the area to be anesthetized. To anaesthetize the mandible, there are many local anaesthesia methods that target the inferior alveolar nerve, which runs along the mandibular canal.
The conventional inferior alveolar nerve block has been used frequently in various procedures for many years. However, the success rate of the inferior alveolar nerve block is, in fact, only modest and associated complications, such as aspiration and nerve injury, are fairly common. Thus, various anaesthesia methods for inferior nerve block (Figure 1) have been continuously studied to try to address this issue [2]. The conventional inferior alveolar nerve block (IANB) is the most commonly used nerve block technique in dentistry. This technique involves anaesthesia of the inferior alveolar nerve, which enters the mandibular foramen, via the positioning of the needle on the mandibular foramen area. The crucial clinical landmarks of this technique are the coronoid notch and pterygomandibular raphe. The insertion point is located 3/4 down the line drawn from the deepest part of the pterygomandibular raphe to the coronoid notch. The needle must be advanced until the bone is contacted. Aspiration is mandatory prior to 
administration of the local anaesthetics and administration should be done very slowly. The nerves anesthetized are the inferior alveolar, incisor, mental, and lingual nerves. The mandibular teeth to the midline, the body of the mandible, the lower part of the mandibular ramus, buccal periosteum and mucous membrane to the premolars, anterior $2 / 3^{\text {rd }}$ of the tongue, oral floor, lingual soft tissue, and the periosteum are all anesthetized. The failure rate of the conventional inferior alveolar nerve block is greater than $20 \%$. Anatomical variations of the mandible and insufficient insertion depth into the soft tissue are thought to be the key factors in nerve block failure [3]. Traditionally, pain management in the mandible, especially in the molar region, is far more complex than in the maxilla which can be measured with Visual Analogue scale (VAS). The conventional inferior alveolar nerve block has potential risks including neural or vascular injury. Takasugi et al. introduced a technique that can eliminate such risks. As opposed to the conventional technique, in which the needle tip is directed at the mandibular foramen, this technique positions the needle anterior to the mandibular foramen. Boonsiriseth et al. [4] have introduced a technique for achieving anaesthesia of the inferior alveolar nerve without periosteum contact. The insertion point is the same as that of the conventional inferior alveolar nerve block and the syringe is positioned parallel to the mandibular occlusal plane of the same side of the surgical site. The insertion depth is controlled by a rubber stop. A $30 \mathrm{~mm}$ needle is used and, with the rubber stop positioned at 20 $\mathrm{mm}$, the needle is advanced until the rubber stop makes contact. As the needle does not contact the periosteum, this technique provides less pain compared to the conventional technique and reduces the frequency of positive aspiration and the risk of neural or vascular injury [5]. The Fischer 1-2-3 technique, which is also called the indirect technique, requires the identification of several anatomical landmarks such as external oblique ridge, coronoid notch, apex of buccal pad of fat, pterygomandibular raphe and the retromolar pad. During the course of injection in the first stage 3-6mm distance, second stage $12 \mathrm{~mm}$ distance, and in the third stage $24 \mathrm{~mm}$ distance of needle insertion to be made from $42 \mathrm{~mm}$ length needle. Since there are no markings in the needle it is difficult to apply by operators. As the height of the mandibular foramen from occlusal plane is $11 \mathrm{~mm}$, the selection of site of initial needle penetration is 12 to $16 \mathrm{~mm}$ above the occlusal plane and also it is essential to insert the needle to a distance of 20 to 25 $\mathrm{mm}$ from anterior border to reach the space above mandibular foramen, then the needle tip would be nearer and above the nerve entry. In this way the tip of needle is placed superior to mandibular foramen, on complete insertion of 22 to $24 \mathrm{~mm}$ needle distance from the anterior border [6]. In 1977, Akinosi brought this method to the attention of educators, but they soon realized that this technique had been published by Vazirani in 1960. The objective is to place the needle tip between the ramus and the medial pterygoid muscle.
This technique is used when the patient is in a closedmouth position. Local anesthetic is injected into the superior position of the pterygomandibular space. In this technique the needle is inserted to its predetermined depth. The needle is positioned at the level of the maxillary marginal gingiva, parallel to the maxillary occlusal plane. The syringe is advanced posteriorly, and the needle penetrates approximately $2.5 \mathrm{~cm}$ to $3 \mathrm{~cm}$ into the soft tissues in the embrasure between the mandibular ramus and the maxillary tuberosity. This technique has advantages like it delivers anesthetic more proximally than the conventional block, leading to a larger area of anesthesia and a reduced chance that accessory innervation will cause failure, it Blocks the long buccal nerve, obviating the need for a separate injection. Since this technique utilizes a closed-mouth approach, so it gives a clear advantage when trismus frustrates administration of the injection. However, it does have its share of disadvantages like it is difficult to visualize the path and depth of needle penetration and there is no bony contact. It also deals with complications like hematoma, facial nerve paralysis as well as trismus in rare cases [7].

\section{AIM OF THE STUDY}

The purpose of the present study was to assess the efficacy as well as pain perception status in patients, who have been administrated Inferior Alveolar Nerve Block (IANB) for third molar extraction by both closed mouth as well as open mouth techniques.

\section{METHODOLOGY}

90 patients were enrolled in the present study. The patients were given inferior alveolar nerve block to extract mandibular third molar by three different techniques. They were divided in 3 groups of 30 patients each.

Group I-30 in conventional open mouth technique of IANB

Group II- 30 in Fischer 123 technique

Group III- 30 in closed mouth Vazirani-Akinosi technique

Pain Perception (VAS) (Figure 2) Speed of anaesthesia, Patient anxiety and Clinician expertise were measured

\section{RESULTS}

The result show that intra-oral conventional technique is less technique sensitive as compared to Vazirani-Akinosi and Fischer's 123 techniques. Former is still the best in terms of less expertise required as well as pain perception by the patient. (Table 1) However, pain perception in Vazirani-Akinosi technique for patients on VAS is less as compared to conventional as well as indirect Fischer's 123 techniques. Even the former has faster spread of anaesthesia also. 


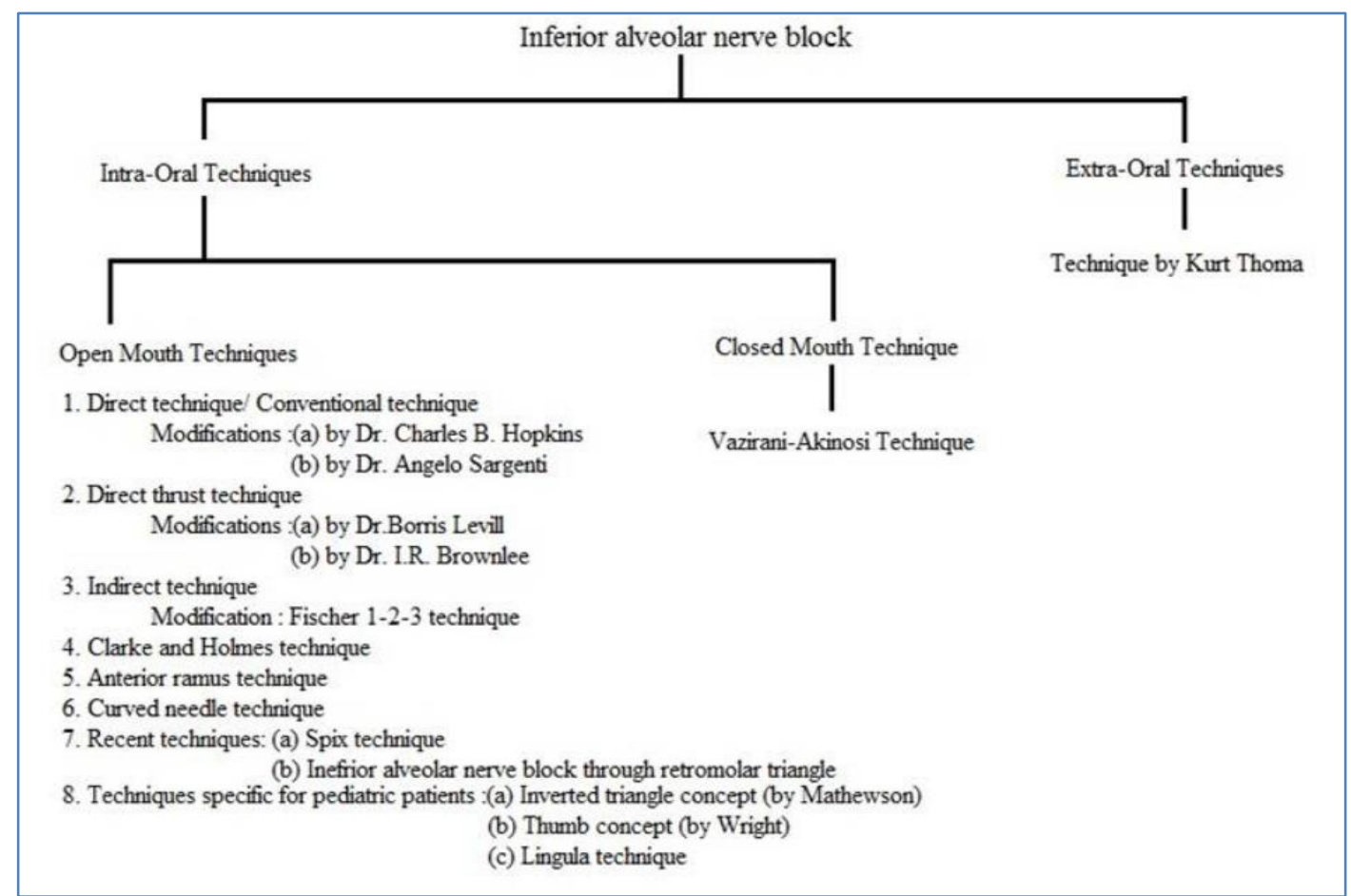

Fig-1: Classification of Inferior Alveolar Nerve Blocks

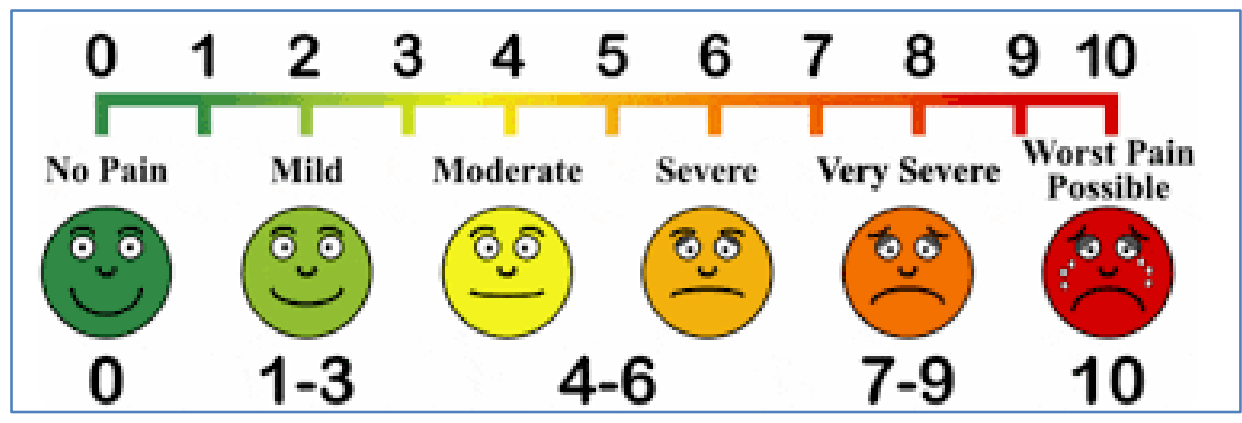

Fig-2: VAS Scale for Pain Measurement

Table-1: Various parameters of efficacy and pain perception in the present study

\begin{tabular}{|l|l|l|l|l|}
\hline Groups & Pain Perception (VAS) & Speed of anaesthesia & Patient anxiety & Clinician expertise \\
\hline I & 3 & moderate & Mild to moderate & Normal level \\
\hline II & 4 & moderate & moderate & Moderate level \\
\hline III & 2 & fast & High & High level \\
\hline
\end{tabular}

*VAS- Visual Analogue Scale - 0-10

\section{DISCUSSION}

Inferior alveolar nerve block (IANB) is a technique used to produce anesthesia of the mandibular teeth, gingiva of the mandible, and the lower lip. These procedures anaesthetize the inferior alveolar nerve (IAN) prior to entering the mandibular foramen. Although IANB is a routine block injection administered regularly in dental practice, failure to achieve satisfactory levels of analgesia is noticed in few cases [8]. Predictable anesthesia is an essential requirement for both the patient and the dentist in Dentistry. The patient's opinion about his dental treatment is closely related to the local anesthesia experiences he has had. The proper use of local anesthesia techniques and pain management are indispensable for successful dental treatment. IANB is the most commonly used nerve block technique in extraction of lower teeth and other minor surgeries done in mandible. Various techniques are in current use to anesthetize the IAN. (Figure 1) Each technique has its advantages and disadvantages [9]. Infiltration techniques have shown extremely high success rates in the maxilla but seem to have disappointing figures when made in the lower molar region. Most authors recommend IANBs when a dental treatment is being made in this region. However, this technique can be difficult to perform especially because the anatomical landmarks used are not always reliable, and also be- 
cause of the long distance between the injection point and the area where the local anaesthetic is finally placed. This fact along with the considerably high positive aspiration rate shows the need for alternative techniques to the traditional IANB [10]. Most dentists choose IANB as it is familiar to them and worked in most situations. There have been a lot of studies which have compared the efficacy of conventional with Vazirani-Akinosi technique, which have claimed that less amount of LA was required with far less complications in comparison to conventional IANB technique. However, many authors like Malamed claimed that conventional, direct technique is better as level of anesthesia depth is commendable rather than indirect Fischer's technique. Moreover, another disadvantage which Fischers 123 technique suffers is that there is possibility of over penetration which may result in facial palsy as there are no markings in the needle it is difficult to apply by operators.

\section{CONCLUSION}

Conventional open mouth technique is still the most popular choice amongst clinicians and the pain sensitivity is also negligible amongst the patients with this classic intra-oral technique. Indirect as well as closed mouth technique requires more skilled expertise but can be used in cases with limited mouth opening.

\section{REFERENCES}

1. Syarif, A., Estuningtyas, A., Setiawati, A. (2012). Farmakologi dan terapi. 5th ed. Jakarta: FKUI, 259-261.
2. Kim, C., Hwang, K.C., Park, C.J. (2018). Local anaesthesia for mandibular third molar extraction $\mathrm{J}$ Dent Anesth Pain Med, 18(5):287-294.

3. Malamed, S.F. (2004). Handbook of Local Anaesthesia. 5th ed. St Louis, Mosby.

4. Takasugi, Y., Furuya, H., Moriya, K., Okamoto, Y. (2000). Clinical evaluation of inferior alveolar nerve block by injection into the pterygomandibular space anterior to the mandibular foramen. Anesth Prog, 47: 125-129.

5. Boonsiriseth, K., Sirintawat, N., Arunakul, K., Wongsirichat, N. (2013). Comparative study of the novel and conventional injection approach for inferior alveolar nerve block. Int J Oral Maxillofac Surg, 42: 852-856.

6. Tangavelu, K., Kannan, R., Kumar, N.S. (2012). Inferior alveolar nerve block: Alternative technique. Anaesthesia: essays and researches, 6(1):53-57.

7. Anuradha, M., Yashavanth, Kumar, D.S., Harsha, V.B., Rahul, S. (2014). Variants of inferior alveolar nerve block. CODS J Dent, 6; 35-39.

8. Madan, G.A., Madan, S.G., Madan, A.D. (2002). Failure of inferior alveolar nerve block: Exploring the alternatives. J Am Dent Assoc, 133:843-846.

9. Kohler, B. R., Castellón, L., \& Laissle, G. (2008). Gow-Gates technique: a pilot study for extraction procedures with clinical evaluation and review. Anesthesia progress, 55(1), 2-8.

10. Vasconcelos, B. C., Freitas, K. C., \& Canuto, M. R. (2008). Frequency of positive aspirations in anesthesia of the inferior alveolar nerve by the direct technique. Medicina oral, patologia oral $y$ cirugia bucal, 13(6), E371-4. 